\title{
Weight-Making Practices Among Jockeys: An Update and Review of the Emergent Scientific Literature
}

\section{Kelly Ryan \\ Joseph Brodine}

Department of Family Medicine, Medstar Franklin Square Medical Center,

Baltimore, MD, USA

\begin{abstract}
Numerous publications have described the behaviors employed by professional jockeys on a daily basis to achieve and maintain a minimum racing weight. This narrative review provides an update of recent publications that report on the impact of such practices. Although rapid weight-loss techniques such as calorie restriction and dehydration are commonly thought to be deleterious to jockeys, little evidence exists of enduring health consequences. There is evidence to suggest that jockey training behaviors and dietary choices are not aligned with optimum preparation for the physiological demands of the sport. Further research is necessary to better measure the health impact of jockey weightmaking behaviors; such data might guide reforms of athlete behavior and regulatory practices within the global sport of horse racing.

Keywords: jockey, jockey health, horse racing, athlete, nutrition, bone density, body weight
\end{abstract}

\section{Introduction}

The athletes of competitive horse racing - one of the most popular sports worldwide ${ }^{1,2}$ ride in a crouch position of forward propulsion atop an unpredictable thoroughbred racehorse typically weighing approximately $500 \mathrm{~kg}$ racing at maximum speeds of 60 $70 \mathrm{~km} / \mathrm{h}$. The magnitude of this near-daily feat is belied only by the off-field necessity of keeping their body mass at minimum year-round. Over the past few decades, researchers have studied the practices jockeys employ to "make weight" with respect to their efficacy and their impact on health outcomes. New insights into the physiological demands of riding have called into question typical exercise practices. Studies describing both typical and experimental nutrition patterns suggest a need to shift away from the practice of severe caloric restriction. Investigations of athletes' physiological responses and health-related consequences of weight-making behaviors call for scrutiny of the minimum weight requirements that have historically governed this sport. In this narrative review of published, peer-reviewed literature, the authors provide an update on the growing body of research on the subject of jockey weight-making practices and offer a brief analysis with recommendations for future research.

\section{Methodology}

A targeted literature search using PubMed, Ovid, Google Scholar, and SCOPUS was performed. Studies were identified using combinations of the following key search terms: 'jockey’ AND “nutrition” OR “horse-racing” OR “bone density” OR “weight.” 
Results were filtered according to date and those published in 2014 and beyond were identified for review to provide an update since the review published by Wilson et al. ${ }^{10}$ Selected papers published before that year were included when no other recent publications were available or when their substance was necessary for context. Published studies included reviews, cross-sectional studies, and quasi-experimental designs. In November 2019, the International Conference for Health, Welfare, and Safety of Jockeys (ICHWJS) was held in Dubai, UAE; this conference served as another source of information. The actual search and collection of articles was conducted from June 2020 to December 2020.

\section{Physical Demands of Horseracing}

Jockeys must possess optimal cardiovascular fitness and targeted muscle strength to satisfy the physiological demands of the sport. To drive their horse to greater speeds, jockeys must adopt a "martini" glass stance while astride their horse midrace. This stance, described by Kiely et al as a "quasi-isometric squat position", allows the jockey to align their center of gravity with the horse's center of mass while flexing at the knee and thigh to adjust their riding height. This position requires well-developed core strength and lower extremity power to maintain their forward propulsion. ${ }^{3}$ Authors have also described cardiovascular demands of racing with mean heart rate (HR) mid-race ranging from 130s to 180 s and peak heart rate ranging from $150 \mathrm{~s}$ to $190 \mathrm{~s}^{3-6}$ (as described in Table 1. Three studies have estimated in-race mean maximal aerobic capacity $\left(\mathrm{VO}_{2} \max \right)$ ranging approximately 42.74 ( \pm 5.6$)$ to $57.54( \pm 4.71) \mathrm{mL} \mathrm{O}_{2} /(\mathrm{kg} \mathrm{min}) .{ }^{4,5,7}$ Although these physiological demands suggest that professional jockeys must maintain a fitness level on par with other elite athletes, it is unclear whether standard training practices align with the performance needs of the sport and some authors have suggested that there is an over-emphasis on weight management as opposed to cardiovascular and aerobic fitness in jockey training. ${ }^{8}$

\section{Anthropometry}

Traditionally, the horse racing industry has preferred jockeys who possess a relatively slight body habitus and stature. This body type is thought to optimally balance strength with body mass and ostensibly improve finishing times. The average height of a professional jockey is $1.58-1.67 \mathrm{~m}$ with the typical age ranging from mid-twenties to early thirties. ${ }^{9}$ The average body mass index (BMI, $\mathrm{kg} / \mathrm{m}^{2}$ ) of professional jockeys is $20 \mathrm{~kg} / \mathrm{m}^{210}$ and is consistent across various horse racing nations as described in Table 2. Body composition statistics
Table I Mean and Peak Heart Rates

\begin{tabular}{|c|c|c|c|c|}
\hline Year & Author & Study Population & $\begin{array}{c}\text { Mean } \\
\text { HR } \\
\text { (b Min) }\end{array}$ & $\begin{array}{c}\text { Peak } \\
\text { HR } \\
\text { (b Min) }\end{array}$ \\
\hline \multirow[t]{2}{*}{2019} & \multirow[t]{2}{*}{ Grimshaw $^{6}$} & $\begin{array}{l}\text { Male Professional } \\
\text { Jockeys }(n=15)- \\
\text { Simulated Race }\end{array}$ & $134 \pm 16$ & $158 \pm 17$ \\
\hline & & $\begin{array}{c}\text { Male Professional } \\
\text { Jockeys }(n=15) \text {-Live } \\
\text { Race }\end{array}$ & $169 \pm 10$ & $|87 \pm| \mid$ \\
\hline \multirow[t]{2}{*}{2015} & \multirow[t]{2}{*}{ Cullen $^{7}$} & $\begin{array}{l}\text { Male Trainee Jockeys } \\
(n=18) \text {-Simulated } \\
\text { Race }\end{array}$ & $144 \pm 15$ & $161 \pm 16$ \\
\hline & & $\begin{array}{c}\text { Male Apprentice } \\
\text { Jockeys }(n=8) \text {-Live } \\
\text { Race }\end{array}$ & $180 \pm 6$ & $189 \pm 5$ \\
\hline \multirow[t]{4}{*}{2020} & \multirow[t]{4}{*}{ Kiely $^{3}$} & $\begin{array}{l}\text { Jump Jockeys-Live } \\
\text { Race Short }(n=10)\end{array}$ & $\begin{array}{l}|8| . \mid \\
\pm 8.0\end{array}$ & $\begin{array}{l}192.0 \\
\pm 6.0\end{array}$ \\
\hline & & $\begin{array}{l}\text { Jump Jockeys-Live } \\
\text { Race Long }(n=10)\end{array}$ & $\begin{array}{l}182.0 \\
\pm 9.0\end{array}$ & $195 \pm 9.0$ \\
\hline & & $\begin{array}{c}\text { Flat Jockeys - Live Race } \\
\text { Short }(n=10)\end{array}$ & $\begin{array}{l}172.0 \\
\pm 15\end{array}$ & $\begin{array}{r}190.0 \\
\pm 12.0\end{array}$ \\
\hline & & $\begin{array}{c}\text { Flat Jockeys_Live Race } \\
\text { Long }(n=10)\end{array}$ & $\begin{array}{l}151.0 \\
\pm 19.0\end{array}$ & $\begin{array}{r}186.0 \\
\pm 14.0\end{array}$ \\
\hline
\end{tabular}

tend to include body fat percentage (BF\%), a critical metric as body fat plays a central role in metabolic efficiency. ${ }^{11} \mathrm{~A} \mathrm{BF} \%$ of $5 \%$ is considered the minimum requirement for health. ${ }^{11,12}$ Relative to $\mathrm{BMI}$, the average jockey $\mathrm{BF} \%$ varies depending on geography. Studies describing athlete anthropometrics calculate mean $\mathrm{BF} \%$ of jockeys in Great Britain at 11-13\% $(n=37),{ }^{9,13}$ while mean $\mathrm{BF} \%$ of Irish flat and national hunt jockeys has been reported at $9-10.5 \%(\mathrm{n}=27)^{11}$ and in another study as $8-14 \%(\mathrm{n}=30) .{ }^{14}$ Among jockeys in South Korea, mean $\mathrm{BF} \%$ has been reported at $14.4 \%(\mathrm{n}=10)^{15}$ and among jockeys in Hong Kong, 5.84\% $(\mathrm{n}=20){ }^{4}$ A study by Warrington et al described a cohort of 27 Irish professional jockeys; of those, $88 \%$ of flat jockeys and $60 \%$ of national hunt jockeys had a BF\% of $<10 \%$ and $24 \%$ of flat and $20 \%$ of national hunt jockeys had body fat $<6 \%{ }^{11}$ In contrast, Jackson et al measured $\mathrm{BF} \%$ in 175 newly licensed jockeys in Great Britain and found that mean $\mathrm{BF} \%$ was $14.6 \pm 2.3$ among 79 male flat jockeys, $15.7 \pm 2.7$ among 69 male national hunt jockeys, and $24.4 \pm 3.7$ among 37 female flat jockeys. ${ }^{16}$ Those authors noted that their measurements were higher than those body fat percentages previously described in the literature and posited that their relatively larger sample size may reflect a recruitment bias 
Table 2 Jockey Anthropometry

\begin{tabular}{|c|c|c|c|c|c|c|c|c|}
\hline $\begin{array}{l}\text { Study } \\
\text { Year }\end{array}$ & Author & Study Population & Country & $\begin{array}{c}\text { Mean } \\
\text { Age (Years) }\end{array}$ & Mean Height & $\begin{array}{l}\text { Weight } \\
\text { (kg) }\end{array}$ & $\begin{array}{c}\text { BMI } \\
\left(\mathbf{k g} \cdot \mathrm{m}^{-2}\right)\end{array}$ & $\begin{array}{l}\text { Mean Body } \\
\text { Fat \% } \\
\text { (DEXA) }\end{array}$ \\
\hline 2017 & O'Reilly ${ }^{4}$ & $\begin{array}{l}\text { Male Professional Flat } \\
\qquad(n=20)\end{array}$ & Hong Kong & $29.3 \pm 7.8$ & $162 \pm 6 \mathrm{~cm}$ & $53.8 \pm 3.3$ & $20.5 \pm 1.5$ & - \\
\hline \multirow[t]{2}{*}{2013} & \multirow[t]{2}{*}{ Wilson ${ }^{42}$} & $\begin{array}{l}\text { Male Professional Flat } \\
\qquad(n=19)\end{array}$ & $\begin{array}{l}\text { Great } \\
\text { Britain }\end{array}$ & $27 \pm 5$ & $167 \pm 5.3 \mathrm{~cm}$ & $56.1 \pm 2.9$ & $20.3 \pm 1.4$ & $13.0 \pm 3$ \\
\hline & & $\begin{array}{l}\text { Male Professional Jump } \\
\qquad(n=25)\end{array}$ & & $29 \pm 5$ & $175 \pm 4.9 \mathrm{~cm}$ & $65.3 \pm 2.5$ & $21.4 \pm 1.3$ & $11.5 \pm 3.3$ \\
\hline 2018 & Poon ${ }^{23}$ & $\begin{array}{l}\text { Male Professional Flat } \\
\qquad(n=14)\end{array}$ & Hong Kong & $29.1 \pm 6.1$ & $52.8 \pm 3.7 \mathrm{~cm}$ & $52.8 \pm 3.7$ & $20.3 \pm 1.6$ & - \\
\hline 2018 & Jeon ${ }^{15}$ & $\begin{array}{l}\text { Male Professional (>5 } \\
\text { Years of Experience) } \\
\qquad(n=10)\end{array}$ & $\begin{array}{l}\text { South } \\
\text { Korea }\end{array}$ & $31.8 \pm 3.7$ & $157.5 \pm 4.52 \mathrm{~cm}$ & $50.6 \pm 1.87$ & $20.5 \pm 1.38$ & $14.4 \pm 2.27$ \\
\hline \multirow[t]{2}{*}{2020} & \multirow[t]{2}{*}{ Kiely $^{3}$} & $\begin{array}{l}\text { Male Professional Flat } \\
\qquad(n=10)\end{array}$ & Ireland & $26.6 \pm 6$ & $168.0 \pm 5.0 \mathrm{~cm}$ & - & - & - \\
\hline & & $\begin{array}{l}\text { Male Professional Jump } \\
\qquad(n=10)\end{array}$ & & $25 \pm 4$ & $174.0 \pm 5.0 \mathrm{~cm}$ & - & - & - \\
\hline 2019 & Kiely $^{5}$ & Male Trainee $(n=I I)$ & Ireland & $16 \pm 1$ & $1.67 \pm 0.01 \mathrm{~m}$ & $55.2 \pm 6.1$ & $19.9 \pm 1.8$ & \\
\hline \multirow[t]{2}{*}{2015} & \multirow[t]{2}{*}{ Cullen $^{7}$} & Male Trainee $(n=18)$ & Ireland & $16 \pm 1$ & $1.67 \pm 0.05 \mathrm{~m}$ & $55.7 \pm 55$ & $19.9 \pm 1.7$ & $8.1 \pm 4.7$ \\
\hline & & Male Apprentice $(n=8)$ & & $18 \pm 1$ & $1.69 \pm 0.04 \mathrm{~m}$ & $54.9 \pm 2.9$ & $19.2 \pm 1.1$ & $7.4 \pm 1.3$ \\
\hline 2015 & Cullen ${ }^{26}$ & $\begin{array}{l}\text { Male Apprentice Flat } \\
\qquad(\mathrm{n}=12)\end{array}$ & Ireland & $19 \pm 2$ & $1.72 \pm 6.3 \mathrm{~m}$ & $59.8 \pm 4.7$ & $20.3 \pm 1.4$ & - \\
\hline 2017 & Wilson ${ }^{25}$ & $\begin{array}{l}\text { Male Professional Flat } \\
\qquad(n=8)\end{array}$ & & $36.9 \pm 5.7$ & $164.5 \pm 7.5 \mathrm{~cm}$ & $54.6 \pm 2.5$ & - & - \\
\hline \multirow[t]{2}{*}{2017} & \multirow[t]{2}{*}{ Wilson ${ }^{36}$} & $\begin{array}{l}\text { Male Professional Flat } \\
\text { (Apprentice) }(n=17)\end{array}$ & $\begin{array}{l}\text { Great } \\
\text { Britain }\end{array}$ & $19 \pm 2$ & $170 \pm 5 \mathrm{~cm}$ & $56.2 \pm 2$ & - & $13.7 \pm 2.6$ \\
\hline & & $\begin{array}{l}\text { Male Professional Flat } \\
\quad \text { (Senior) }(n=14)\end{array}$ & & $32 \pm 7$ & $166 \pm 5 \mathrm{~cm}$ & $56.4 \pm 3$ & - & $12.5 \pm 1.9$ \\
\hline
\end{tabular}

inherent to earlier studies where smaller samples of jockeys already interested in their body composition had been enrolled. ${ }^{16}$ This observation appears validated by Dunne et al, where the accuracy of six separate predictive equations for $\mathrm{BF} \%$ that used skin-fold measurements was compared to $\mathrm{BF} \%$ measured by both a novel equation and dual-energy $\mathrm{x}$-ray absorptiometry (DEXA). That study demonstrated a wide variance and under-estimation by traditional skin-fold tests while describing very high correlation $(0.9<r<1)$ between the predictions of their proposed novel $\mathrm{BF} \%$ estimation equation and DEXA measurements of BF\%. Based on their findings, Dunne et al argue that $\mathrm{BF} \%$ has likely been underestimated in prior studies and they call for a more athlete-specific method of BF\% estimation in future research. ${ }^{17}$ Of note, several authors have compared jockeys to other weight-restricted athletes and Jackson et al noted that the jockey $\mathrm{BF} \%$ they reported was much higher than published $\mathrm{BF} \%$ of lightweight rowers, wrestlers, cyclist, and boxers. ${ }^{14,16}$

\section{Minimum Weights for Riding}

Weight limits for Flat and National Hunt horse racing vary from country to country. ${ }^{1,10}$ In Great Britain, the minimum weight is $50.8 \mathrm{~kg}$ for flat-racing and $64.0 \mathrm{~kg}$ for national hunt racing. This includes boots, breeches, silks and saddle 
which comprise approximately $4 \mathrm{~kg}$ included in that minimum weights. ${ }^{10,18}$ Weight limits for professional flat and national hunt (jump) racing in Ireland are 52.6 and 61.7$76 \mathrm{~kg}$, respectively, which is also inclusive of all the necessary racing equipment. Apprentice jockeys may race even at lower weights than the stipulated limit due to an additional "allowance" of approximately $4.5 \mathrm{~kg}$ afforded to apprentice jockeys meant to encourage trainers to select less experienced but lighter riders. ${ }^{11,17,19}$ In a study performed by Dolan et al, records of training jockeys over the past 30 years have shown an increase in trainee body mass by $37 \%(13.6 \mathrm{~kg})$, while the minimum weight allocation for flat jockeys increased by only $6 \%{ }^{11,19}$ Racing weights for jockeys in the United States are difficult to determine because there are no uniformly applied standards and racing regulations may vary from state to state. Riders in Maryland, for example, race at a minimum weight of $53.6 \mathrm{~kg}(118 \mathrm{lb})$ without apprentice considerations. ${ }^{20}$ Regardless of the global setting, all local and national racing weight limits are typically $>10 \%$ below the average reference population and have not reflected the changes in mean weights of the reference population for the past century or more. ${ }^{11}$ Most of the authors cited in this review have commented on the growing difference between minimum riding weights and increases in the mean body mass of a modern adult: in the US over the past 20 years alone, the average mass of an adult male has increased by $6.8 \mathrm{~kg}$ despite the average height remaining constant. ${ }^{21}$

\section{Common Training Activities: Metabolic Demand and Energy Balance}

Despite advances in sports medicine and performance training, many practices among jockeys have been passed down across generations of riders uninformed by scientific insights. ${ }^{18}$ A typical working day for a jockey can include riding out, sports specific "work" (fast-paced riding) and "schooling" (specific for races). Additional hours are spent "mucking out" (cleaning out stables), brushing horses and carrying buckets of feed and water, though these activities are more commonly performed by apprentices rather than professional jockeys. ${ }^{22}$ Morning riding activities exert an energetic demand proportional to the speed of the horse's gait. In a study of eleven flat race trainee jockeys, authors described the energy expenditure of specific gaits in units of metabolic equivalent of tasks (METs): trotting and was recorded at 6.2 METs (comparable to tennis doubles or leisurely cycling at $16-19 \mathrm{~km} / \mathrm{h}$ ) while cantering was recorded at 7.7 METs (similar to singles tennis or leisurely cycling at $19-22 \mathrm{~km} / \mathrm{h}$ ). ${ }^{5}$ While these routine exercises place a certain physiological demand on the rider, it is suggested that merely completing these morning riding activities are insufficient to prepare jockeys to meet the demands of racing, and that additional exercise modes should be encouraged, including high-intensity interval training. ${ }^{3,5,7,8}$ High-intensity interval training-particularly those routines that involve prolonged quasiisometric squatting positions with flexion of the hip and knee and culminating in short high-intensity pushing activities - would mimic the demands of riding and result in a sustained peak HR and serum lactate concentrations similar to those measured during a race. ${ }^{5}$

Several recent studies have attempted to quantify energy intake in jockeys. A 2016 study of 20 male jockeys in Hong Kong estimated that jockeys consumed an average of $806 \pm 256 \mathrm{kcal}$ per day, a little over half of their resting metabolic rate requirement. ${ }^{4}$ Those same authors tabulated reported average caloric intake from studies representing five countries which showed an intake ranging 1360-1786 $\mathrm{kcal} /$ day. $^{23}$ In a 2011 study of 21 Irish jockeys, total daily energy intake was estimated as $1803 \pm 564 \mathrm{kcal} /$ day, only $22 \%$ above the resting metabolic rate (RMR) for those athletes. ${ }^{19}$ Other research suggests riders' misconceptions regarding energy balance are likely rooted in jockeys' difficulties understanding and tracking their own energy intake. O'Loughlin et al asked 17 jockeys to report their individual eating patterns while wearing a body camera to assess the difference between reported dietary intake and objectively measured dietary intake. The mean daily energy intake as measured by a combination of diary and camera $(2631 \pm 893.4 \mathrm{kcal} /$ day) was $10.7 \%$ higher than the mean daily energy intake measured by diary alone $(2349 \pm 827.9$ $\mathrm{kcal} /$ day). ${ }^{24}$ This disparity between reported and actual energy intake is perhaps best highlighted in a study by Wilson et al, who used doubly labeled water isotopes to perform indirect calorimetry in order to estimate both total energy expenditure (TEE) and total energy intake (TEI) among a cohort of 8 professional jockeys in Great Britain. The authors studied riders during a period in the spring and in the autumn. They estimated mean daily TEE per season as 10.83 and $10.66 \mathrm{MJ}$, respectively, which exceeded the self-reported TEI of 6.03 and $5.37 \mathrm{MJ}$, respectively. The authors conclude that the discrepancy was most likely explained by "significant under-reporting of dietary 
intake." Their findings led the authors to suggest that conventional dietary wisdom observed by most athletes "(ie, high-CHO and high energy intake) may not apply to professional jockeys" and that daily aerobic exercise would improve strength and conditioning without contributing to increased muscle mass despite many jockeys' misconception that such exercise could impede efforts to make weight. ${ }^{25}$ They further emphasized that mean TEEs measured in the study were modest compared to those of agematched athletes in other sports. ${ }^{25}$ Taken collectively, the recent and growing body of research describing energy balance in jockeys appears to argue against any perception that jockeys are chronically undernourished and that many riders may be negating any benefits of calorie restriction through the disordered eating patterns surrounding race days.

\section{Current Weight Loss Strategies}

Historically, the horse racing industry has observed the assumption that a lighter rider runs a faster race. For generations, jockeys have undertaken a variety of restrictive practices to maintain their mass. ${ }^{26-28}$ Ongoing research continues to describe a ubiquitous reliance on rapid weight loss methods to achieve racing weight limits summarized in Table 3. Most of these strategies are passed down from one generation of riders to the next with limited influence from scientific advancements in the understanding of nutrition and exercise physiology. ${ }^{13}$ Most publications report that jockeys continue to rely on chronic weight cycling and unhealthy practices including severe restrictions on fluid and food intake as well as passive (sauna use) and active (intensive exercise in sweat suits) sweating..$^{10,26,29,30}$ One study of 85 Irish jockeys noted that $55.3 \%$ of the participants reported difficulty with weight management and $67 \%$ reported that they rapidly lost weight at least once a month to race. ${ }^{8}$

Practices known to result in dehydration have been consistently reported over the past two decades across jockey populations globally. A survey of 21 professional Irish jockeys in 2011 recorded that the most popular weight loss strategies were those that would result in dehydration with sauna and exercise-induced diaphoresis reported among more than $80 \%$ of the respondents. Food restriction or fasting was reported by more than half of the respondents. ${ }^{19}$ Similarly, a 2014 study of 8 jockeys from Great Britain found the most common methods of weight-making strategies included exercising in a sweat suit $(100 \%)$, gradual dieting (100\%), sweating in a sauna $(75 \%)$, food restriction (62\%) and fluid restriction (62\%). ${ }^{30}$ In a survey of 20 professional jockeys in Hong Kong in 2016, the most frequently used weight-making techniques included sauna (25.5\%), restricting fluid intake (20.4\%); wearing plastic (19.7\%); excessive exercising $(16.1 \%)$ exercising to sweat $(14.6 \%$ and vomiting (3.6\%). ${ }^{4}$ Of 43 jockeys in South Korea, $80 \%$ reported undergoing weekly weight loss regimens usually

Table 3 Jockey Weight-Making Practices (Reprinted with Permission of Wilson ${ }^{10}$

\begin{tabular}{|c|c|c|c|c|c|c|c|}
\hline Study & $\begin{array}{l}\text { Dolan } \\
(n=2 I)\end{array}$ & $\begin{array}{l}\text { Labadarios } \\
(n=85)\end{array}$ & $\begin{array}{l}\text { Leydon } \\
(n=20)\end{array}$ & $\begin{array}{l}\text { Moore } \\
(n=|| 6)\end{array}$ & $\begin{array}{l}\text { Wilson } \\
(n=8)\end{array}$ & $\begin{array}{l}\text { Jeon }^{15} \\
(n=35)\end{array}$ & $\begin{array}{l}\text { Kiely }^{8} \\
(n=85)\end{array}$ \\
\hline \multicolumn{8}{|l|}{ Method } \\
\hline Sauna & 18 & 65 & 5 & 25 & 7 & 18 & $\mathrm{n} / \mathrm{r}$ \\
\hline Restrict food & 15 & 72 & 6 & 68 & 6 & 9 & $\mathrm{n} / \mathrm{r}$ \\
\hline Restrict fluid & $\mathrm{n} / \mathrm{r}$ & 72 & 6 & $n / r$ & 6 & 7 & $\mathrm{n} / \mathrm{r}$ \\
\hline Salt/hot bath & $n / r$ & 25 & 3 & $\mathrm{n} / \mathrm{r}$ & 3 & $\mathrm{n} / \mathrm{r}$ & $\mathrm{n} / \mathrm{r}$ \\
\hline Exercise to sweat & 9 & 45 & 3 & 69 & 8 & 21 & 25 \\
\hline $\begin{array}{l}\text { Flipping (self-induced } \\
\text { vomiting) }\end{array}$ & 3 & $\mathrm{n} / \mathrm{r}$ & $\mathrm{n} / \mathrm{r}$ & 9 & $\mathrm{n} / \mathrm{r}$ & 2 & $\mathrm{n} / \mathrm{r}$ \\
\hline Diuretics & I & 65 & 2 & 21 & $\mathrm{n} / \mathrm{r}$ & 0 & $\mathrm{n} / \mathrm{r}$ \\
\hline Laxatives & I & 25 & $\mathrm{n} / \mathrm{r}$ & 10 & I & 0 & $\mathrm{n} / \mathrm{r}$ \\
\hline Smoking & 5 & 70 & $\mathrm{n} / \mathrm{r}$ & 44 & $\mathrm{n} / \mathrm{r}$ & $n / r$ & $\mathrm{n} / \mathrm{r}$ \\
\hline
\end{tabular}

Notes: $\mathrm{n} / \mathrm{r}$, not reported in the manuscript or reported in such a way it is not possible to calculated numbers. 
consisting of extreme dieting, exercising, or using a sauna. ${ }^{15}$ Despite a ban on diuretics, there is some evidence that their use continues in many countries, though jockeys are likely reluctant to report taking diuretic medications. ${ }^{10}$

Apprentice jockeys appear to adopt these behaviors during training. In a 2017 series of semi-structured interviews of jockeys and their trainers performed in Great Britain, one jockey describes experimenting with different weight-making practices early in his career: "I guess you sort of experiment seeing what you can do and what you can't do". ${ }^{18}$ A study of 12 apprentice jockeys in Ireland reported reliance on food restriction $(100 \%)$, fluid restriction (100\%), exercising wearing extra clothing/bin bag liners $(75 \%)$, and sauna use $(17 \%) .^{7}$ These reported behaviors appear validated by objective clinical testing. In 2009, Warrington and colleagues analyzed the urinespecific gravity (USg) of 27 jockeys on race days and found that $54 \%$ of the participants were competing in a severely dehydrated state determined by urine-specific gravity. ${ }^{11}$ In the era of the novel coronavirus pandemic, US jockeys have been officially prohibited from using the sauna. The consequence of this restriction has not yet been studied with respect to jockeys' compensatory behaviors or any effect on weight-making or race times.

\section{Perceptions of the Role of Physical Activity}

New research suggests that jockeys may eschew healthy physical activity in favour of less healthy weight-making behaviors due to a misconception that certain exercise will lead to the undesirable effect of increasing muscle mass. In a study by Kiely et al, 85 professional jockeys responded to a questionnaire regarding physical activity practices. And, $77.6 \%$ of jockeys reported that they partake in physical activities outside of riding (commonly, aerobic and gym-based exercise), where almost a quarter of jockeys $(22.4 \%)$ reported no physical activity outside of ridingrelated work. Of those who did not participate in physical activity, reasons included "I don't have time" (42\%), "I am too tired after riding work" (14\%) "I am fit enough from riding work" (14\%), "I don't enjoy it" (8\%), and "I do not want to gain weight $(8 \%){ }^{8}$ The hours jockeys spend riding each morning on non-racing days may further a belief that each athlete has adequately exercised, yet the physical work of these routine activities has been found to fall short of the physiological demands of race riding and may displace opportunities for physical activities that would promote healthy weight-making and specific race preparation. $^{5}$

\section{Health Effects of Weight-Making Practices}

Recently published literature suggests certain effects of weight-making practices on key physiological systems and raises concern for how those behaviors may affect their performance and could potentially increase the occupational risk associated with race riding regardless of geographic training location. Dolan et al surveyed 21 professional Irish jockeys regarding their rapid weight loss strategies; $52 \%$ reported being affected by thirst, $43 \%$ by dehydration, $38 \%$ by hunger, and $33 \%$ by a negative mood state. ${ }^{19}$ In a study of 14 professional jockeys in Hong Kong, the most commonly reported symptom was fatigue $(27.7 \%)$ followed by dehydration $(22.3 \%)$ and headaches $(20 \%){ }^{23}$ In addition to reported symptoms of rapid weight cycling, a number of studies have examined the effects of weight-making practices.

\section{Performance}

A number of authors have tested an association between dehydration and key functional and clinical measures. In most sports, continuous hydration for performance is encouraged as body water and lean tissue are essential for optimal physiological function. ${ }^{11}$ Unlike other weightrestricted athletes, jockeys are weighed up to 10 times during a typical race day and are thus inclined to avoid rehydration or replenishing energy. ${ }^{23}$ Jockeys typically reduce their body mass by $2-3 \%$ on race days ${ }^{30}$ with one study noting a reduction by as much as $4.5 \mathrm{~kg}$ (approx. $6.7 \%$ of body mass) to achieve the desired racing weight. ${ }^{31}$ Wilson et al performed a randomized crossover study of eight professional British jockeys comparing their strength, simulated riding performance, and reaction time in both euhydrated and dehydrated states induced by rapid weight loss practices. Even a $2 \%$ reduction in body mass resulted in statistically significantly increased HR (166 up from $148 \mathrm{bpm}$ ), decreased chest and leg strength, and simulated riding performance. ${ }^{30}$

\section{Cognitive Function}

In that same crossover study of eight professional jockeys in different hydration states, authors noted that there was no significant difference in cognitive function determined by reaction time in the two groups. ${ }^{30}$ The apparent 
inconsequence of dehydration on cognitive function was replicated in a study of 12 apprentice Irish jockeys who induced a $4 \%$ weight loss using their typical rapid weight loss practices. None of the participants demonstrated any significant difference in simple and choice reaction time, attention, or learning and memory compared with age- and gender-matched controls. ${ }^{27}$ This may be because any cognitive function in the setting of rapid weight loss normalizes at about 3.5 hours. ${ }^{32}$ However, the authors noted that the jockeys who participated in this study were slower to respond in the simple reaction test and less accurate in the visual learning and memory task than the controls at baseline raising an interesting question as to whether some long-term cognitive impairment may exist. ${ }^{27}$

\section{Metabolism and Endocrine Function}

The question of long-term health effects was investigated in a 2015 cross-sectional study of 28 retired male jockeys. Cullen et al did not identify any long-term consequences of chronic weight cycling with respect to glucose metabolism or thyroid function. The authors did note enhanced weight gain and raised cholesterol levels compared with non-jockeys within a matched population of older, Irish males. ${ }^{33}$

Other research has explored the impact of jockeys' nutritional intake and weight-making practices on mood and endocrinologic function, specifically, bone health. While bone health is discussed further in the next section, a notable study by Poon et al measured serum testosterone, cortisol, and 25-hydroxyvitamin D in 14 professional jockeys in Hong Kong and did not find any abnormal values or significant difference between jockeys' laboratory levels and those of the matched controls. ${ }^{23}$

\section{Behavioral Health}

Multiple past studies have suggested a link between weight-making behaviors (including disordered eating) and affective and behavioral disorders. In a 2019 crosssectional study comparing professional jockeys $(n=42)$ to amateur jockeys $(n=74)$ in Great Britain, authors noted a higher prevalence of depression, anxiety, and social phobia, and all participants had a higher prevalence of those disorders compared to other elite athletes. The authors report that $50 \%$ of the professional jockey participants reported "cutting weight up to 3 times per week" compared with $9.5 \%$ of amateur jockeys. Despite this disparity, authors also noted that the professional jockeys were almost twice as likely to have had a concussive injury than amateurs and more research would be necessary to elucidate the direct effects of weight-making practice on mental health. ${ }^{34}$ Wilson et al had tested the relationship between weight-making practices and mood in an experimental study of 10 jockeys by measuring their EAT-26 (a validated tool to screen for attitudes consistent with an eating disorder) and GHQ-12 (a validated instrument to measure psychologic distress) scores after 6 weeks of an individualized diet and exercise regimen (based on each participants' RMR). After receiving the intervention - designed to replace typical weight-making practicesthere was no statistically significant reduction in the mean scores of both screening tests. ${ }^{13}$ While Wilson and others have noted that the EAT-26 tool has revealed a significant prevalence of disordered eating behaviors among jockeys, these behaviors are not necessarily linked to body image. Martin et al described the motivation for such behaviors as likely stemming from the need to make weight rather than affect appearance. ${ }^{18}$ The authors of a 2019 cross-sectional study comparing 135 retired jockeys to 675 participants from a reference population noted an increased risk of anxiety and depression among the retired jockeys (adjusted OR 2.81 and 2.60, respectively). They concluded that many factors may have contributed to this increased risk of a mood disorder, but speculated this may be an effect of years of weight-management practices. ${ }^{35}$

\section{Bone Health}

Within the sport of horse racing, the ongoing occupational safety concern for high-speed falls and risk for bone fractures $^{30}$ has focused scientific discussion on optimal bone health. Low bone mineral density (BMD) among jockeys has been consistently reported with many investigators using DEXA to measure BMD in riders as a measure of bone health. A study of 20 professional jockeys in Hong Kong detected osteopenia in the trabecular calcaneus bones of riders (mean $t$-score -1.54 to -1.82 ) though the mean cortical BMD of the forearms was normal (mean $t$-score -0.19 to -0.41$).{ }^{4}$ Those authors would later posit that there is likely a "site-specific bone-loading response to horse racing" that might explain the relatively high BMD scores at the forearms. ${ }^{23}$ Authors studying 27 professional Irish jockeys reported whole-body osteopenia in $53 \%$ of flat $(n=17)$ and $10 \%$ of national hunt $(n=10)$ jockeys with $12 \%$ of the flat jockeys having osteoporosis. The authors also reported a positive relationship between bone mineral density and body mass. ${ }^{11}$ Similar findings were described among a cohort of apprentice jockeys in 
Great Britain: male flat jockeys $(\mathrm{n}=79)$ had lower spine, femoral neck, and total hip BMD compared to male national hunt jockeys $(n=69)$ and both groups had lower spine BMD than female flat jockeys as determined by $z$-scores using 2008 reference data from the NHANES cohort (a representative US cohort followed longitudinally for measures of health and nutrition). The investigators of that study noted that the male jockeys $(n=148)$ were aged 16-22 years old and found to have low BMD at an age when they should be achieving peak bone mass. ${ }^{16}$

The factors that contribute to this apparent low BMD have not been completely elucidated, and much of what is currently published has led researchers to infer a link between low BMD and riders' weight-making practices. ${ }^{36}$ For example, O’Reilly et al hypothesized that the low BMD observed among 20 professional jockeys in Hong Kong may have in part resulted from none of the participants meeting the estimated average requirement of calcium or vitamin $\mathrm{D} .{ }^{4}$ Wilson et al challenged that assumption with a cross-sectional study comparing the BMD of apprentice jockeys $(n=17)$ with an average of 3.4 years of race riding experience with the BMD of senior jockeys $(n=14)$ who had been racing professionally for an average of 16 years. While both groups had low lumbar BMD (mean $z$-scores of -1.3 vs -1.5 ), there was no significant difference between the groups. The authors interpreted the data as suggesting that the low BMD was more likely due to a lack of osteogenic stimulus rather than low-energy availability given prior evidence of jockeys' under-reporting their own nutritional intake. ${ }^{36}$ A 2018 study showed 13 out of 14 professional jockeys in Hong Kong had osteopenia or osteoporosis in at least one of their calcanei, yet they had no difference in micronutrient intake (calcium and vitamin D) compared to age and BMI-matched controls who possessed relatively higher BMD. Of note, the bone-specific physical activity questionnaire (BPAQ) responses of the jockeys scored lower than those of the controls suggesting that bone-specific activities may have an outsized impact on BMD. ${ }^{23}$ This perspective appears to be supported by earlier research suggesting that limb acceleration forces for all riding gaits (1.21-3.64 g) are not much greater than walking $(2.25 \mathrm{~g})$ and significantly less than running (13.18 g) ${ }^{37}$ It is also unclear whether low BMD among jockeys can be prevented by dietary interventions alone. In a randomized controlled trial comparing bone density (using peripheral quantitative computer tomography $[\mathrm{pQCT}]$ ) and bone turnover markers), participants were given calcium and vitamin $\mathrm{D}(\mathrm{n}=8)$ or placebo $(\mathrm{n}=9)$ for 6 months. At the end of the trial period, there was significant evidence of suppression of bone resorption but no significant difference in bone density. ${ }^{38}$
Other factors described in the literature with potential association with low BMD include smoking and alcohol consumption, and though no direct correlation has been investigated, one author noted that 12 out of 21 Irish jockeys surveyed reported smoking to maintain their weight, a practice that is associated with low BMD in other populations. ${ }^{19}$ Other researchers found that fracture history may at least be predictive of low BMD. ${ }^{15}$

The consequences of this widely reported low BMD among jockeys are unclear. Suboptimal bone density is hypothesized to be attributed to the disruption of endocrine profiles involved in growth and repair ${ }^{19,23}$ and some research has suggested an increased risk of osteoporosis among retired jockeys. ${ }^{35}$

With regards to the use of DEXA to measure BMD, the publications included in this review collectively acknowledge some degree of apprehension regarding the clinical utility of this metric when used with jockeys. Authors have noted that the unique physical stature of jockeys places them in a uniquely "atypical" category that may not be easily compared to reference populations used to power DEXA interpretations. ${ }^{36}$ Other authors have suggested using bone mineral area density (BMAD) or pQCT in order to compare volumetric data. ${ }^{14,36}$ Several researchers suggest future research should use larger cohorts, prospective study designs for longitudinal follow-up, and, when possible, histochemical tissue analysis for definitive pathologic confirmation of osteopenia/osteoporosis. ${ }^{36}$

\section{Evidence for Reformed Approaches to Weight Management}

Recent research may offer the scientific basis for revising current weight-making practices that typically include rapid weight loss techniques rooted in tradition rather than grounded in fact. Wilson et al studied the effect of replacing typical dietary patterns and exercise routines with an individualized diet and a fitness plan that focused on aerobic training while fasting and generally refraining from intentional sweat-inducing activities (eg, wearing sweat-suits). Jockeys were prescribed a high protein/low carbohydrate diet where the protein and fat content were held constant, but carbohydrate intake was titrated to a TEI that slightly exceeded each participants' resting metabolic rate. After 6 weeks of this intervention, mean body mass (including $\mathrm{BF} \%)$ significantly decreased $(59.2 \mathrm{~kg}$ vs $57.6 \mathrm{~kg} ; 13.1 \%$ vs $11.5 \%$, respectively) along with RMR $\left(1703 \pm 329\right.$ vs $\left.1975 \pm 313 \mathrm{kcal}^{-1} \mathrm{~d}^{-1}\right)$ and $\mathrm{VO}_{2 \max }(3.8 \pm 0.8$ vs 
4.1 $\pm 0.7 \mathrm{~L} / \mathrm{m}^{-1}$ ). Notably, chest strength, leg strength, and jumping height all significantly increased though no structured resistance training was included in the intervention. ${ }^{13}$ Those same authors later suggested that conventional athletic diets high in carbohydrates may not be applicable to jockeys given their modest TEE. ${ }^{25}$

The Wilson group has also questioned the current minimum weights for riding. Guided by the premise that a minimum of $2.5 \mathrm{~kg}$ of absolute fat mass is the lowest fat mass required to suppress lean muscle catabolism, investigators assessed the body composition of 32 male apprentice jockeys in Great Britain using DEXA. The mean total body mass for the group was $56 \mathrm{~kg}$ correlating to a theoretical lowest mean body mass of $51.2 \mathrm{~kg}$, a difference of $0.4 \mathrm{~kg}$ over the minimum riding weight in Great Britain for flat racing of $50.8 \mathrm{~kg}$. Authors postulated that only a single jockey in their cohort (3.1\%) would be able to achieve this minimum weight and maintain at least $2.5 \mathrm{~kg}$ in body fat - a conclusion that suggests current minimum racing weights are inherently unhealthy for average modern male riders who typically rely on rapid weight cycling practices to achieve that minimum. ${ }^{39}$

With evidence to suggest that daily riding activities are inadequately serving as training for the more physiologically demanding race riding, some authors have called for race preparation that involves more bespoke sportsspecific strength and conditioning including highintensity interval training. ${ }^{5,8}$ The benefits of resistance training that mimics the intensity of race riding include both performance improvement as well as body composition and bone health. ${ }^{8}$

\section{Discussion}

\section{Key Themes}

As the number of publications on jockey health has increased over the past few decades, traditional weightmaking and physical preparation strategies for riding have emerged as a focal point for discussion. The studies presented in this review collectively indicate a need for industry-wide reform of common dietary practices and exercise regimens. Jockeys appear to underestimate their energy intake while needlessly restricting their nutritional intake in a manner that does not benefit their performance and may result in certain adverse health consequences. Typical dietary practices tend to be low in essential micronutrients and high in carbohydrates, an unnecessarily increased energy supply that is overmatched for the modest total daily energy demands of the sport. Similarly, usual exercise regimens do not seem to benefit a rider's metabolism or comprise of sports-specific conditioning. The light morning riding activities of jockeys along with as many as a half-dozen rides on a race day may take up many hours of a jockey's day but only amount to about 45 minutes of strenuous activity-substantially less than a professional athlete playing a different sport. The apparent absence of routine aerobic endurance and high-intensity strength training may derive from a misconceived aim to avoid adding undesired muscle mass coupled with the perception that daily riding practices on non-racing days are adequate for preparation. In an analysis of race days in New Zealand over a 14-year study period, Legg et al found that a minority of starting flat race jockeys (23\%) performed the majority of race day rides (83\%) highlighting an "inefficiency" within the industry and underscoring the need for a training regimen commensurate to race day demand. ${ }^{40}$

Researchers have consistently labelled jockeys' weight-making practices as dangerous or harmful. Some investigators have measured the degree of dehydration and the effect of these practices on riders' moods in an effort to quantify deleterious consequence. Despite the intuitive reasoning behind this perception, there is little evidence of any particular chronic morbidity or acute injury associated with the weight-making practices in question. Indeed, some authors have speculated that the extreme weight loss jockeys can achieve within a matter of hours, though dangerous to a typical adult human, might be well tolerated by athletes who have become physiologically habituated to these practices. ${ }^{11,26,27}$

This review highlighted the evolution of research on jockeys' bone health. Early reports of low BMD appropriately raised concerns for increased fracture risk, yet the reasons for this apparently ubiquitous finding are unclear and the population-specific relative risk has not been quantified. Recent publications appear to increasingly favour a hypothesis of low osteogenic impact as the predominant etiology over other factors such as nutrition or lifestyle. In the absence of epidemiological data attributing health outcomes to measured BMD, investigators have consistently questioned the utility of BMD as a measure of risk owing to problematic interpretation of DEXA imaging data in this unique population. It is notable that none of the publications featured in this review nor any other publications known to the authors have associated an increased risk of bone fracture with the putative low BMD of jockeys, nor 
is low BMD known to be associated with adverse pathology among older or retired jockeys.

\section{Limitations}

The search process for publications was limited to a narrative review method. While sports medicine in horse racing remains a relatively small body of literature and the total number of peer-reviewed articles touching on jockey weight-making practices number fewer than a hundred, a systematic or technical review may have afforded the authors a greater degree of academic rigor with a greater number of articles identified in the initial search.

Within the literature itself, there are limitations. Though investigators are careful to distinguish between apprentice and professional jockeys, the data are often reported in aggregate and the overall combined populations make up small $(n \leq 20)$, mostly male sample sizes that are unique to those few countries where the publishing scientists have access to jockey populations. For example, there is a dearth of research on US jockey nutrition and exercise practices which may be as much affected by the cultural practices of individual riders as the specific influences of the sport. Another limitation of the studied population is the possibility of a form of self-selection bias. A recent study of jockey career length found that out of 674 riders in New Zealand, $40 \%(n=272)$ quit by the end of their second year and half of those quit within their first year of racing. Those who remained in the sport were more likely to be male and more likely to be under 18 years old at the start of their career. While the determinants of this reportedly high early dropout rate are not fully understood, the authors suggest that the ability to tolerate continuous weight-making practices is likely a deterrent to would-be professionals. ${ }^{41}$ If that hypothesis were correct, it would be reasonable to associate the longevity of professional riders with their apparent tolerance of the lifestyle, a tolerance that may be as much physiological as psychological. It could be argued that these elite athletes are less prone to the presumed harms of rapid weight loss through a combination of physical habituation and natural capacity for extreme variance in energy balance.

\section{Future Research}

The conclusions of the research presented in this review shed additional light on the underlying impetuses and consequences of jockey weight-making practices while implicitly suggesting the direction where future insights may be gained.
An important question for future researchers to address and with which the industry must ultimately reckon is how to develop standard guidelines for training. Until there are specific standards built on a clear scientific evidence base and recommended by industry authorities, jockeys and trainers may likely remain inert in their daily routines possessed by a sensibility deferential to tradition.

Absent any evidence-based guidelines, inspiring change will remain a challenge without a better understanding of the harms of current practices. Though common sense would incline any health advocate to warn jockeys of the harms of extreme chronic weight cycling, there is a need to better understand the chronic impacts this has on various health outcomes with respect to permanent end-organ injury and mortality risk.

There is also a need to better understand the health beliefs and current knowledge that govern jockeys' choices in weight-making. Martin et al conducted a series of semi-structured interviews that aimed to explore the perceptions of weight-making practices among jockeys and their trainers. One jockey is quoted as commenting on eating practices,

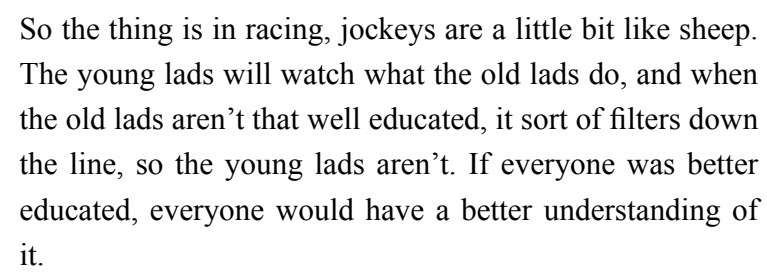

The authors identify a lack of education as the emergent theme of their analysis and conclude that

jockeys are entering the industry with little or no theoretical or applied knowledge of nutrition and weightmanagement in a sport where the necessity to manage weight is greater than any other sport based on their need to make weight every day. ${ }^{18}$

Future research could build on this work to perform knowledge assessments of jockey populations in order to quantify athletes' nutritional knowledge or even test the efficacy of interventional strategies that could include education initiatives.

\section{Conclusion}

The science describing the effects and weight-making practices among jockeys continues to mature and offer new insights. While future research could serve as a guide for athletes and trainers in a paradigm-shift towards healthier 
nutritional behaviors and exercise regimens that more closely align with the actual physical demands of the sport, broader questions remain regarding the long-term effects of participating in a sport with unforgiving minimum riding weight limits. Both athletes and the horse racing industry must heed the science and move to embrace evidence-based practices as investigators continue to refine our understanding and better measure the consequences of this aspect of one of the world's most popular sports.

\section{Acknowledgment}

The authors would like to acknowledge Jarett Beaudoin, MD, MPH and Dan Martin, PhD for their collegial contributions to this review.

\section{Disclosure}

The authors report no conflicts of interest in this work.

\section{References}

1. Ryan KD, Brodine J, Pothast J, McGoldrick A. Medicine in the sport of horse racing. Curr Sports Med Rep. 2020;19(9):373-379. doi:10.1249/JSR.0000000000000750

2. Turner M, McCrory P, Halley W. Injuries in professional horse racing in Great Britain and the Republic of Ireland during 1992-2000. Br J Sports Med. 2002;36(6):403-409. doi:10.1136/bjsm.36.6.403

3. Kiely M, Warrington GD, McGoldrick A, Pugh J, Cullen S. Physiological demands of professional flat and jump horse racing. $J$ Strength Cond Res. 2020;34(8):2173-2177. doi:10.1519/ JSC.0000000000003677

4. O'Reilly J, Cheng Lun H, Poon Tsz-Chun E. New insights in professional horse racing; "in-race" heart rate data, elevated fracture risk, hydration, nutritional and lifestyle analysis of elite professional jockeys. $J$ Sports Sci. 2017;35(5):441-448. doi:10.1080/ 02640414.2016.1171890

5. Kiely MA, Warrington GD, McGoldrick A, O'Loughlin G, Cullen S. Physiological demands of daily riding gaits in jockeys. J Sports Med Phys Fitness. 2019;59(3):394-398. doi:10.23736/S00224707.18.08196-3

6. Grimshaw B. Differences in head accelerations and physiological demand between live and simulated professional horse racing. In: Quintana C, Rockwood HE, Heebner NJ, Johnson AK, Ryan KD, Mattacola CG, editors Comparative Exercise Physiology. 2019.

7. Cullen S, O'Loughlin G, McGoldrick A, Smyth B, May G, Warrington GD. Physiological demands of flat horse racing jockeys. $J$ Strength Cond Res. 2015;29(11):3060-3066. doi:10.1519/ JSC.0000000000000977

8. Kiely M, Warrington G, McGoldrick A, Cullen S. Physical preparation strategies of professional jockeys. J Strength Conditioning Res. 2020; Publish Ahead of Print. doi:10.1519/JSC.0000000000003514

9. Wilson G, Fraser WD, Sharma A, et al. Markers of bone health, renal function, liver function, anthropometry and perception of mood: a comparison between Flat and National Hunt Jockeys. Int $J$ Sports Med. 2013;34(5):453-459. doi:10.1055/s-0032-1321898

10. Wilson G, Drust B, Morton JP, Close GL. Weight-making strategies in professional jockeys: implications for physical and mental health and well-being. Sports Med. 2014;44(6):785-796. doi:10.1007/ s40279-014-0169-7
11. Warrington G, Dolan E, McGoldrick A, et al. Chronic weight control impacts on physiological function and bone health in elite jockeys. J Sports Sci. 2009;27(6):543-550. doi:10.1080/02640410802702863

12. Going S. Body Composition. Davis R, editor. Baltimore, MD: Lipincott, Williams \& Wilkins; 2001.

13. Wilson G, Pritchard PP, Papageorgiou C, et al. Fasted Exercise and Increased Dietary Protein Reduces Body Fat and Improves Strength in Jockeys. Int J Sports Med. 2015;36(12):1008-1014. doi:10.1055/ s-0035-1549920

14. Dolan E, Crabtree N, McGoldrick A, Ashley DT, McCaffrey N, Warrington GD. Weight regulation and bone mass: a comparison between professional jockeys, elite amateur boxers, and age, gender and BMI matched controls | springerLink. J Bone Miner Metab. 2012;20(2):164-170. doi:10.1007/s00774-011-0297-1

15. Jeon S, Cho K, Ok G, Lee S, Park H. Weight loss practice, nutritional status, bone health, and injury history: a profile of professional jockeys in Korea. J Exerc Nutrition Biochem. 2018;22(3):27-34. doi:10.20463/jenb.2018.0021

16. Jackson KA, Sanchez-Santos MT, MacKinnon AL, et al. Bone density and body composition in newly licenced professional jockeys. Osteoporos Int. 2017;28(9):2675-2682. doi:10.1007/s00198-0174086-0

17. Dunne A, Warrington G, McGoldrick A, et al. Estimation of Body Fat Percentage in Jockeys: implications for a Weight Category Sport. Int J Exerc Sci. 2020;13(4):511-525.

18. Martin D. The horseracing industry's perception of nutritional and weight-making practices of professional jockeys. In: Wilson G, Morton JP, Close GL, Murphy RC, editors. Qualitative Research in Sport and Exercise2017. 2014:1-15.

19. Dolan E, O'Connor H, McGoldrick A, O’Loughlin G, Lyons D, Warrington G. Nutritional, lifestyle, and weight control practices of professional jockeys. J Sports Sci. 2011;29(8):791-799. doi:10.1080/ 02640414.2011.560173

20. Laurel Park Condition Book. 2021. Available from: https://www. laurelpark.com/horsemen/condition-book. Accessed June 10, 2021.

21. Statistics CNCfH. Men, Women, Kids All Heavier, Not Much Taller Than 20 Years Ago. CDC. Available from: https://www.cdc.gov/ nchs/pressroom/nchs_press_releases/2016/201608_Height_Weight. htm. Accessed June 10, 2021.

22. Wilson G, Andy S, DrustBarry PM, Morton JP, Close GL. Assessment of energy expenditure in elite jockeys during simulated race riding and a working day: implications for making weight. Applied Physiol Nutrition Metab. 2013;38(4):415-420. doi:10.1139/ apnm-2012-0269

23. Poon ET-C, O’Reilly J, Sheridan S, Cai MM, Heung-Sang Wong S. Markers of Bone Health, Bone-Specific Physical Activities, Nutritional Intake, and Quality of Life of Professional Jockeys in Hong Kong. Int J Sport Nutr Exerc Metab. 2018;28(4):440-446. doi:10.1123/ijsnem.2016-0176

24. O'Loughlin G, Cullen SJ, McGoldrick A, et al. Using a wearable camera to increase the accuracy of dietary analysis. Am J Prev Med. 2013;44(3):297-301. doi:10.1016/j.amepre.2012.11.007

25. Wilson G, Lucas D, Hambly C, Speakman JR, Morton JP, Close GL. Energy expenditure in professional flat jockeys using doubly labelled water during the racing season: implications for body weight management. Eur J Sport Sci. 2017;18(2):235-242. doi:10.1080/ 17461391.2017.1406996

26. Cullen S, Dolan E, Brien KO, McGoldrick A, Warrington G. Lack of effect of typical rapid-weight-loss practices on balance and anaerobic performance in apprentice jockeys. Int J Sports Physiol Perform. 2015;10(8):972-977. doi:10.1123/ijspp.2014-0506

27. Cullen S, Dolan E, McGoldrick A, Kate OB, Carson BP, Warrington $\mathrm{G}$. The impact of making-weight on cognitive performance in apprentice jockeys. J Sports Sci. 2015;33(15):1589-1595. doi:10.1080/02640414.2014.1002104 
28. Cullen S, Donohoe A, McGoldrick A, et al. Musculoskeletal health, kidney and liver function in retired jockeys. Int J Sports Med. 2015;36(12):968-973. doi:10.1055/s-0035-1548889

29. Dolan E, McGoldrick A, Davenport C, et al. An altered hormonal profile and elevated rate of bone loss are associated with low bone mass in professional horse-racing jockeys. J Bone Miner Metab. 2012;30(5):534-542. doi:10.1007/s00774-012-0354-4

30. Wilson G, Hawken MB, Poole I, et al. Rapid weight-loss impairs simulated riding performance and strength in jockeys: implications for making-weight. J Sports Sci. 2014;32(4):383-391. doi:10.1080/ 02640414.2013.825732

31. Wilson G, Chester N, Eubank M, et al. An alternative dietary strategy to make weight while improving mood, decreasing body fat, and not dehydrating: a case study of a professional jockey. Int J Sport Nutr Exerc Metab. 2012;22(3):225-231. doi:10.1123/ijsnem.22.3.225

32. Cian C, Barraud PA, Melin B, Raphel C. Effects of fluid ingestion on cognitive function after heat stress or exercise-induced dehydration. Int $J$ Psychophysiol. 2001;42(3):243-251. doi:10.1016/s01678760(01)00142-8

33. Cullen S, Donohoe A, McGoldrick A, et al. Physiological and health characteristics of ex-jockeys. J Sci Med Sport. 2016;19(4):283-287. doi:10.1016/j.jsams.2015.05.001

34. Losty C, Warrington G, McGoldrick A, Murphy C, Burrows E, Cullen S. Mental health and wellbeing of jockeys. Sport Med Nutrition Health. 2019;14.

35. Mackinnon AL, Jackson K, Kuznik K, et al. Increased risk of musculoskeletal disorders and mental health problems in retired professional jockeys: a cross-sectional study. Int J Sports Med. 2019. doi:10.1055/a-0902-8601
36. Wilson G, Martin D, Morton JP, Close GL. Male flat jockeys do not display deteriorations in bone density or resting metabolic rate in accordance with race riding experience: implications for RED-S. Int J Sport Nutr Exerc Metab. 2018;28(4):434-439. doi:10.1123/ ijsnem.2017-0371

37. Cullen SJ, Warrington G, Dolan E, etal. An analysis of the impact forces of different modes of exercise as a causal factor to the low bone mineral density in jockeys. Int Conference Biomechanics. 2014:4-33.

38. Silk L, Greene D, Baker M, Jander C. The effect of calcium and vitamin D supplementation on bone health of male Jockeys - Journal of Science and Medicine in Sport. J Sci Med Sport. 2017;20 (3):225-229. doi:10.1016/j.jsams.2016.08.004

39. Wilson G, Hill J, Martin D, Morton JP, Close GL. GB Apprentice Jockeys Do Not Have the Body Composition to Make Current Minimum Race Weights: is It Time to Change the Weights or Change the Jockeys? Int J Sport Nutr Exerc Metab. 2020;1-4. doi:10.1123/ijsnem.2019-0288

40. Legg K. The External Workload of Thoroughbred Horse Racing Jockey. In: Cochrane D, Gee E, editors. Sustainability. 2020:7572.

41. Legg K, Cochrane D, Gee E, Rogers C. Jockey Career Length and Risk Factors for Loss from Thoroughbred Race Riding. Sustainability. 2020;12(18):7443. doi:10.3390/su12187443

42. Wilson G, Sparks SA, Drust B, Morton JP, Close GL. Assessment of energy expenditure in elite jockeys during simulated race riding and a working day: implications for making weight. Appl Physiol Nutr Metab. 2013;38(4):415-420. doi:10.1139/apnm-2012-0269

\section{Publish your work in this journal}

Open Access Journal of Sports Medicine is an international, peerreviewed, open access journal publishing original research, reports, reviews and commentaries on all areas of sports medicine. The manuscript management system is completely online and includes a very quick and fair peer-review system. Visit http://www.dovepress. $\mathrm{com} /$ testimonials.php to read real quotes from published authors. 